\title{
ПРАВОВОЙ РЕЖИМ ЭЛЕКТРИЧЕСКОЙ ЭНЕРГИИ КАК ОБЪЕКТА ОТНОШЕНИЙ ПО ПЕРЕДАЧЕ ЭЛЕКТРИЧЕСКОЙ ЭНЕРГИИ ПО ЭЛЕКТРИЧЕСКИМ СЕТЯМ
}

\section{THE LEGAL REGIME OF ELECTRIC ENERGY AS AN OBJECT OF RELATIONS FOR THE TRANSMISSION OF ELECTRIC ENERGY THROUGH ELECTRIC NETWORKS}

A. Manucharian

Summary. This article presents the author's view of the legal regime of electrical energy as an object of relations for the transmission of electrical energy through electrical networks. The importance of a consolidated legal understanding of the concept of electrical energy as an object of relations for the transmission of electrical energy through electrical networks is indicated. The approaches used in the implementation of tariff regulation in terms of differentiation of electrical energy (power) are considered. The necessity of developing productive and scientifically grounded approaches to this problematics at the integrative stage of development of the legal system is substantiated. Conclusions are formulated regarding the application of market mechanisms in the circulation of electrical energy in the wholesale and retail markets of electrical energy (capacity).

Keywords: electric power industry, energy law, state regulation, legal regime of electric energy, energy resources, fuel and energy complex.

\author{
Манучарян Арсен Юрьевич \\ Аспирант, Российская академия народного \\ хозяйства и государственной службы при Президенте \\ Российской Федерации (РАНХиГС) \\ Arsen803366@gmail.com
}

Аннотация. В данной статье представлен авторский взгляд на правовой режим электрической энергии как объекта отношений по передаче электрической энергии по электрическим сетям. Обозначена важность консолидированного правопонимания понятия электрической энергии как объекта отношений по передаче электрической энергии по электрическим сетям. Рассмотрены подходы, применяемые при осуществлении тарифного регулирования в части дифференциации электрической энергии (мощности). Обоснована необходимость выработки продуктивных и научно-обоснованных подходов к данной проблематике на интегративном этапе развития системы права. Сформулированы выводы, касающиеся применения рыночных механизмов при обращении электрической энергии на оптовых и розничных рынках электрической энергии (мощности).

Ключевые слова: электроэнергетика, энергетическое право, государственное регулирование, правовой режим электрической энергии, энергоресурсы, топливно-энергетический комплекс.

Говоря о технологических особенностях электрической энергии как отдельного, самостоятельного ресурса, необходимо отметить, что в правопонимании тарифного регулирования, понятие электрическая энергия (мощность) как правило используется в сочетании с понятием «напряжение».

Напряжение электрической энергии это в первую очередь техническая характеристика энергоустановки, которая позволяет определить для какого уровня напряжения предназначено то или иное энергопринимающее устройство. Необходимо выделить то, что понятие «напряжение» и понятие «уровень напряжения» не являются идентичными.

В свою очередь уровень напряжения - это понятие, которое используется в том числе в нормативных правовых актах, регулирующих порядок и процесс установления тарифов на услуги по передаче электрической энергии, которая в свою очередь дифференцируют- 
ся по уровням напряжения. Так в соответствии с пунктом 48 Правил недискриминационного доступа к услугам по передаче электрической энергии, [2] тарифы на услуги по передаче электрической энергии устанавливаются в соответствии с Основами ценообразования в области регулируемых цен (тарифов) в электроэнергетике [3] и Правилами государственного регулирования (пересмотра, применения) цен (тарифов) в электроэнергетике, [4] с учетом пункта 42 настоящих Правил. В свою очередь в пункте 42 упомянутых Правил определено, что при установлении тарифов на услуги по передаче электрической энергии ставки тарифов определяются с учетом необходимости обеспечения равенства единых (котловых) тарифов на услуги по передаче электрической энергии для всех потребителей услуг, расположенных на территории соответствующего субъекта Российской Федерации и принадлежащих к одной группе (категории) из числа тех, по которым законодательством Российской Федерации предусмотрена дифференциация тарифов на электрическую энергию (мощность).

Таким образом необходимость применять принцип дифференциации тарифов на электрическую энергию - прямо предусмотрен законом. Дифференциация тарифов на электрическую энергию (мощность) реализуется путем расчета и установления цен (тарифов) на услуги по передаче электрической энергии исходя из номинальных классов напряжения (уровней напряжения) электрической энергии. Пунктом 81 (1) Основ ценообразования в области регулируемых цен (тарифов) в электроэнергетике [5] предусматривается, что единые (котловые) тарифы дифференцируются по следующим уровням напряжения:

- высокое первое напряжение $(\mathrm{BH} 1)$ - объекты электросетевого хозяйства и (или) их части, переданные в аренду организацией по управлению единой национальной (общероссийской) электрической сетью территориальным сетевым организациям с учетом требований пунктов 7 и 8 статьи 8 Федерального закона «Об электроэнергетике», [6] за исключением таких объектов и (или) их частей, находящихся на территориях Амурской области и Еврейской автономной области;

- высокое напряжение (ВН) - объекты электросетевого хозяйства (110 кВ и выше), за исключением случаев, которые относятся к $\mathrm{BH} 1$;

- среднее первое напряжение $(\mathrm{CH} 1)$ - объекты электросетевого хозяйства (35 кВ);

- среднее второе напряжение $(\mathrm{CH} 2)$ - объекты электросетевого хозяйства (20-1 кВ);

- низкое напряжение $(\mathrm{HH})$ - объекты электросетевого хозяйства (ниже 1 кВ).

В отраслевом законодательстве, регулирующим расчет цен (тарифов) на услуги по передаче электри- ческой энергии на розничном рынке также предусматривается дифференциация по четырем уровня напряжения, а именно пунктом 44 Методических указаний по расчету регулируемых тарифов и цен на электрическую (тепловую) энергию на розничном (потребительском) рынке [7] предусматривается, что размер тарифа на услуги по передаче электрической энергии рассчитывается в виде экономически обоснованной ставки, которая в свою очередь дифференцируется по четырем уровням напряжения в точке подключения потребителя (покупателя, другой энергоснабжающей организации) к электрической сети рассматриваемой организации:

- на высоком напряжении: (BН) 110 кВ и выше;

- на среднем первом напряжении: (CH1) 35 кB;

- на среднем втором напряжении: (CH11) 20-1 кB;

- на низком напряжении: $(\mathrm{HH})$ 0,4 кВ и ниже.

При этом при сопоставлении электрической энергии, с таким энергоресурсом как нефть, можно выделить определенное сходство, которое заключается в том, что нефтепродукты также могут дифференцироваться, в частности в некоторых отраслевых нормативных правовых актах упоминается такой сорт Российской нефти как REBCO (Russian Export Blend Crude Oil), [8] Urals (смесь, поставляемая преимущественно из Западной Сибири, а также добываемой в Ханты-Мансийском и Ямало-Ненецком автономных округах, Башкортостане, Татарстане и Самарской области), [9] ESPO (East Siberia Pacific Ocean - нефть, поставляемая по трубопроводу Восточная Сибирь Тихий океан). [10]

Указанная дифференциация нефтепродукта происходит исходя из места его добычи, в частности данный параметр может повлиять на ценообразование и стоимость конечного продукта, в том время как применительно к электрической энергии такой фактор как место происхождение (в нашем случае - генерации) электрической энергии не имеет качественного значения.

Электрическая энергия, как объект хозяйственных отношений представляет особое значение при реализации её на товарных рынках.

Так, в целях реализации электрической энергии на товарном рынке между субъектами электроэнергетики заключаются договоры энергоснабжения.

Договор энергоснабжения [11] это особый отраслевой договор, которым закрепляются обязательства поставщика электрической энергии предоставить согласованный объем электрической энергии потребителю, наряду с договором энергоснабжения зачастую заключаются договоры купли продажи электрической энергии (мощности), договоры поставки электриче- 
ской энергии и т.д. при этом перечисленные договоры по своей правовой структуре являются однородными, так как преследуют единую цель - обеспечение энергоснабжения конечного потребителя, о чем свидетельствуют их схожие существенные условия:

- предмет договора;

- дата и время начала исполнения обязательств по договору;

- требования к качеству поставляемой электрической энергии;

- порядок определения объема покупки электрической энергии (мощности) за расчетный период;

- порядок определения стоимости электрической энергии (мощности), поставленной по договору энергоснабжения;

- право одностороннего отказа от договора энергоснабжения со стороны потребителя.

Полный перечень существенных условий договора энергоснабжения приведен в Основных положениях функционирования розничных рынков электрической энергии.

Особое внимание стоит обратить на такое существенной условие договора энергоснабжения как право одностороннего отказа от договора энергоснабжения со стороны потребителя. В данном случае к подобным правоотношениям применимы гражданско-правовые принципы соразмерности. Так Статьей 423 Гражданского кодекса Российской Федерации определен принцип возмездности (эквивалентности), согласно которому, договор, по которому сторона должна получить плату или иное встречное предоставление за исполнение своих обязанностей, является возмездным, соответственно ресурсы, которые затрачены на исполнение обязательства, должно экономически соответствовать предполагаемой оплате.

В случае ненадлежащего исполнения обязательств, а также несвоевременного оформления договорных отношений, не освобождают потребителя от уплаты фактически понесенных расходов, в том числе потребителя от обязанности возместить стоимость отпущенной ему энергии, что соответствует статье 544 Гражданского кодекса Российской Федерации, где указано, что оплата энергии производится за фактически принятое абонентом количество энергии в соответствии с данными учета энергии. Указанные доводы также подтверждаются и судебной практикой.

Одновременно с этим необходимо отметить, что В процессе реализации электрической энергии потребителю посредством договора энергоснабжения, на ресурсоснабжающие организации возлагается обязанность урегулировать отношения, связанные с передачей электрической энергии, путем заключения договора оказания услуг по передаче электрической энергии с сетевой организацией.

Таким образом, заключение договора на услуги по передаче электрической энергии оказания услуг, являются неотъемлемой частью процесса поставки электрической энергии потребителям,

На основании изложенного можно сделать вывод, что правовой режим электрической энергии как объекта отношений по передаче электрической энергии по электрическим сетям может рассматриваться как с точки зрения присущих данном виду энергетических ресурсов технологических особенностей, так и с точки зрения объекта хозяйственной деятельности и (или) товара, обращаемого на рынках электрической энергии (мощности).

При этом наибольший интерес как с теоретической, так и с практической точки зрения представляет обозначение электрической энергии в качестве объекта, обладающего особыми хозяйственными свойствами, иными словами товара, который приобретают участники рынка электрической энергии.

Наибольшее регуляторное воздействие среди отраслей топливно-энергетического комплекса сосредоточено именно в отрасли электрической энергии, это обусловлено как уникальным материальным устройством данного энергоресурса, так и постоянно растущем интересом со стороны субъектов хозяйственной деятельности. В связи с этим, насыщение данной отрасли действенных рыночных механизмов наиболее актуально в последнее время, к таким механизмам в том числе относятся:

- развитый оптовый и розничный рынок электрической энергии,

- саморегулирование в регулируемых сферах деятельности (установление требований к качеству и надежности товаров и услуг, разрешение споров при заключении и исполнении договоров между регулируемыми организациями и потребителями и др.).

Наличие рыночных механизмов саморегулирования отрасли электроэнергетики не отменяет необходимость административного воздействия со стороны органов исполнительной власти Российской Федерации тем или иным образом направлено на:

а) соблюдение баланса интересов участников отношений;

б) повышение качества товаров и услуг посредством развития объектов инфраструктуры с преимущественным привлечением частных инвестиций;

в) создание благоприятных условий для привлечения частных инвестиций, в том числе путем гарантирования доходности и возвратности инвестиций; 
г) обеспечение преемственности и сбалансированности в регулировании тарифов с учетом подходов, отраженных в действующих отраслевых законодательных актах, включая сохранение применения действующих методов регулирования тарифов и корректировки долгосрочных тарифов с учетом объективных факторов (отклонения фактических величин инфляции, полезного отпуска, и т.п.) и неучтенных при установлении тарифов экономически обоснованных расходов;

д) отражение возможности определения в отраслевых законодательных актах приоритетных методов развития топливно-энергетического комплекса, с учетом особенностей соответствующих сфер деятельности.

При этом необходимо отметить, что наличие механизмов саморегулирования не всегда способно поло- жительно влиять на формирование правовых институтов отрасли электроэнергетики.

Например, включение потребителей непосредственно в процесс принятия решений в сфере тарифного регулирования создает конфликт интересов, что будет противоречить основному принципу соблюдения баланса экономических интересов поставщиков и потребителей электрической энергии, закрепленному Законом об электроэнергетике. [12]

Для соблюдения баланса интересов вполне достаточно органа регулирования, обладающего профильной компетенцией, осознающего сопутствующие риски и защищающего права потребителей. При этом действующее законодательство предоставляет потребителям эффективные механизмы защиты их законных интересов путем оспаривания в судебном и административном порядке решений об установлении тарифов.

\section{ЛИТЕРАТУРА}

1. П. 1 ст. 2 Федерального закона от 23.11.2009 № 261-Ф3 «0б энергосбережении и о повышении энергетической эффективности и о внесении изменений в отдельные законодательные акты Российской Федерации» // СЗ РФ. 2009. № 48. ст. 5711.

2. Правила недискриминационного доступа к услугам по передаче электрической энергии и оказания этих услуг, утвержденные постановлением Правительства Российской Федерации от 27.12.2004 № 861 // СЗ РФ. 2004. № 52. Ст. 5525.

3. Основы ценообразования в области регулируемых цен (тарифов) в электроэнергетике, утвержденные постановлением Правительства Российской Федерации от 29.12.2011 № 1178 // СЗ РФ. 2012. № 4. Ст. 504.

4. Правила государственного регулирования (пересмотра, применения) цен (тарифов) в электроэнергетике, утвержденных постановлением Правительства Российской Федерации от 29.12.2011 № 1178 // СЗ РФ. 2012. № 4. Ст. 504.

5. Основы ценообразования в области регулируемых цен (тарифов) в электроэнергетике, утвержденные постановлением Правительства Российской Федерации от 29.12.2011 № 1178 // С3 РФ. 2012. № 4. Ст. 504.

6. Федеральный закон от 26.03.2003 № 35-Ф3 «06 электроэнергетике» // СЗ РФ. 2003. № 13. ст. 1177.

7. Энергетическая стратегии России на период до 2030 года. Утверждена Распоряжением Правительства Российской Федерации 0т 13.11.2009 г. № 1715 р // С РФ. 2009. № 48. Ст. 5836.

8. Пункт 2 Правил мониторинга цен на нефть сырую марки «Юралс» на мировых рынках нефтяного сырья (среднеземноморском и роттердамском) (утверждены Постановлением Правительства Российской Федерации от 26.02.2013 г. № 155 // СЗ РФ. 2013. № 9. Ст. 951).

9. Правила расчета средних за истекший налоговый период цен на соответствующие товары углеводородного сырья, добытые на новом морском месторождении углеводородного сырья (Утверждены Постановлением Правительства Российской Федерации от 23.09.2014 г. № 973 // С3 РФ. 2014. № 39. Ст. 5268).

10. Статья 539 Гражданский кодекс Российской Федерации. Часть вторая: Федеральный закон от 26.01.1996 № 14-Ф3 // СЗ РФ. 1996. № 5. Ст. 410.

11. Пункт 40 Основных положений функционирования розничных рынков электрической энергии, утвержденных постановлением Правительства Российской Федерации от 04.05.2012 № 442 // С3 РФ. 2012. № 23. Ст. 3008.

12. Пункт 6 федерального закона от 26.03.2003 № 35-Ф3 «06 электроэнергетике» // СЗ РФ. 2003. № 13. ст. 1177.

(с) Манучарян Арсен Юрьевич ( Arsen803366@gmail.com ). 